\title{
Food Storage and Transport
}

By Dr. Franklin Kidd, Superintendent of the Low Temperature Research Station, Cambridge

THE state of affairs to-day with regard to the transport and storage of foods is very different from what it was twenty-five years ago The bulk that is handled is very much larger and the variety is much greater, and transport and storage are conducted over longer times and distances.

Putting aside canning and drying as methods of preservation, and considering fresh foodstuffs only, this development has been due to the application of refrigeration over a wider and wider field.

The success that has attended this development is founded on the intelligent grasp that has been everywhere shown of the fact that the use of low temperature as such is in itself only the widest of general principles. Each type of foodstuff, be it fresh fish, meat, fruit or vegetable, is an infinitely complex material and subtly varying according to its growth and development. The last twenty-five years have seen a great extension of our knowledge of the laws governing the changes in these organisms in their living and post-mortem states. To-day, scientific attention is given not only to the question of temperature control and to the maintenance of low temperatures during storage; but also to every stage of the pre- and post-storage history, with the object of producing foodstuffs, after long storage and transport, indistinguishable in appearance, palatability, digestibility and physiological value from the original fresh material.

A single example may be interesting here in illustration. It must be generally known what a difficult fruit the William pear is to handle even when grown in one's own garden. It seems almost incredible that thousands of tons of this choice fruit should be successfully shipped in bulk to Great Britain from South Africa, California and Australia. This success could not be achieved unless in the first place an elaborate scientific technique existed for the proper production of the fruit, free from all blemishes : if the exactly right time for gathering the fruit based on a variety of tests had not been chosen : if the fruit had not been wrapped and systematically packed in cases by methods which have been evolved and standardised as a result of a long process of experiment and observation : if the fruit had not been rapidly cooled in special pre-cooling stores in the country of origin; if afterwards it had not been carried, of necessity in bulk, but with the arrangements of stowage and refrigeration by forced air movement so adjusted as to maintain a uniformity of temperature throughout the hold to within $1^{\circ} \mathrm{F}$. : and if finally, the fruit had not been properly ripened at a controlled high temperature after arrival in Great Britain in the winter months. Disasters occur even to-day through failure in one or other of the links in this chain.

Chilled beef is another good case in point illustrating this type of development. The degree to which the quality of imported chilled beef approximates to that of the best 'home-killed' depends not only on the maintenance of the low temperature, but also its maintenance to within $0 \cdot 5^{\circ} \mathrm{F}$. during shipment: upon the proper breeding, feeding, resting and watering of the cattle before slaughter : and above everything upon the utmost care in the maintenance of hygienic conditions during the dressing of the meat. Bacterial counts are now made at the time the beef is chilled, and from these the condition of the meat on arrival after transport can be almost precisely foretold.

One line along which much progress has been made is in the definition of the optimum temperatures for storage, and this is so principally with regard to fruit, and with regard to frozen fish and meats. As a general principle, all fruits and vegetables have what is termed a low temperature tolerance limit. They cannot of course be frozen without damaging the essential organisation of the fresh product. Even above the freezing point, however, they cannot be stored too long below their tolerance limit without suffering from some form of functional breakdown and disorganisation. Many types of breakdown of this class have now been detected and described in various fruits, and in a large number of cases the optimum temperature of storage has been accurately determined

In the case of frozen fish and frozen meats, scientific analysis has brought to light the fact that changes affecting solubility of the proteins occur most rapidly between $-2^{\circ} \mathrm{C}$. and $-3^{\circ} \mathrm{C}$., and it has become clear that the dry tasteless condition previously encountered in frozen fish and certain meats can be avoided and the fresh state almost completely preserved if, in freezing and thawing, the material is taken rapidly enough through a critical range of temperatures below the freezing point, and if during storage it is held at a temperature between $-20^{\circ} \mathrm{C}$. and $-30^{\circ} \mathrm{C}$.

One of the results of this discovery has been to open up a new source of fish supply to Great Britain. Large vessels equipped with rapid freezing equipment and large storage capacity are able 
to spend months away from port on the west coast of Greenland fishing for halibut and cod. An even more recent development, still in the experimental stage, is the preservation of a proportion of the herring harvest by quick freezing and low-temperature storage for subsequent, out of season, kippering and other uses.

So far we have dealt with what might be described as improvements in the technique of storage by the use of low temperature. A revolutionary development which has taken place within the last twenty-five years, a development which is probably even now only in its infancy, is the regulation of the composition of the atmosphere as an additional or accessory means of controlling biological change.

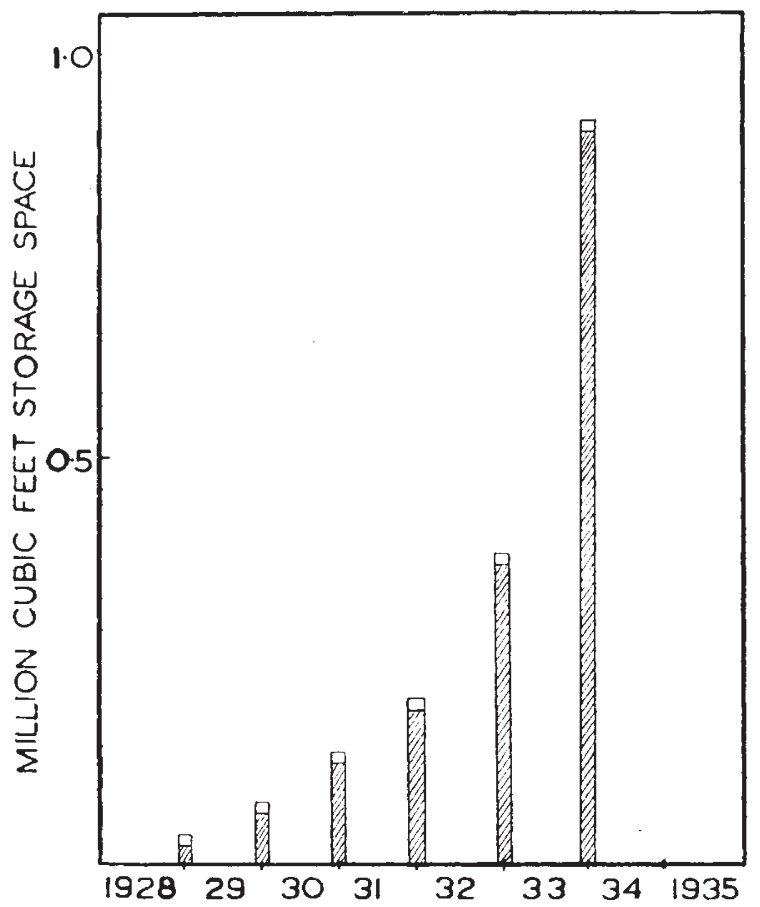

Fit. 1. Increase in the capacity \& gas-storage for apples in England, since 1929 .

The idea of using an inert gas for the better preservation of foodstuffs is, of course, an old one. Modern developments in Great Britain may be said to have started with a series of papers which appeared in the Proceedings of the Royal Society in 1914-15, dealing with the respiration and germination of seeds as affected by oxygen concentration and carbon dioxide concentration. The Food Investigation Board, founded in 1917, took up from the beginning a systematic study of the question of applying the principle of atmosphere control to the storage and transport of food. In the first place, investigations were confined to fruit and fruit-rotting fungi. The first commercial fruit store employing the combined control of the temperature, oxygen and carbon dioxide content of the air was installed in Kent in 1928, and since then the adoption of atmospheric control in fruit stores (gas-storage) has been rapid in Great Britain (Fig. 1).

The effectiveness of the method is due to several facts. The majority of English apples have a relatively high low-temperature tolerance limit, so that cold storage is not effective in the majority of cases for preservation beyond Christmas or January. The rate of ripening is a function of the rate of respiration, and this can be retarded not only by lowering the temperature, but also by reducing the oxygen content of the air and by raising the carbon dioxide content. There are, however, strict limits to which either operation can be safely carried without injuring the fruit. Carbon dioxide has a specific effect also in delaying the onset of what is known as the climacteric, a critical change of state which precedes the ripening changes of softening, and odour and flavour development.

Twenty-five years ago, owing to the length of the voyage, the transport of chilled beef from Australia to Great Britain was an outstanding and apparently insoluble problem. The limit for chilling was set by the activity of the micro-organismsbacteria and moulds. Could the rate of growth of these organisms be sufficiently reduced by any concentration of carbon dioxide which could safely be used without itself spoiling the appearance of the meat? Laboratory experiments on the types of micro-organisms concerned, at the temperatures of chilled beef carriage, indicated that the life of the beef would be approximately doubled by employing an atmosphere containing 10 per cent carbon dioxide. Simultaneous investigations showed that this concentration would be without appreciable effect upon changes in the fat leading to rancidity or those in the hæmoglobin leading to browning. In 1933, the first shipment of gasstored chilled beef was brought, from New Zealand, and to-day there is an established trade in good quality chilled beef from the antipodes to Great Britain.

The possibilities of atmosphere control are not limited to those dependent upon carbon dioxide and oxygen effects upon organisms-fruits, regetables and micro-flora. As the result of the analysis of the critical part played by oxygen in the breakdown of unsaturated fatty acids and the production of certain types of rancidity, many types of dry foodstuffs containing fats are to-day packed in gas-tight containers from which oxygen is excluded. In the storage of bacon or cured pigs' flesh, this type of oxidative rancidity is usually the limiting factor, and storage in the chilled or frozen state does relatively little to retard these oxidative 
changes in fat They can, however, be eliminated by the use of atmospheres free from oxygen and containing a high carbon dioxide content, and by this method bacon can now be successfully stored for months as compared with weeks previously possible.

Other improvements in the science and art of food storage and transport are dependent upon the use in special cases and for special purposes of atmospheres containing regulated traces of such gases as ozone, ethylene and ammonia. Ozone removes undesirable substances from storage atmospheres, such as the 'volatiles' of ripening fruit, which in too high a concentration are harmful to the fruits themselves or 'taint' other products stored afterwards or simultaneously in the same space. Ozone can also exercise a retarding effect on bacterial and mould growth. Ethylene is used specifically to stimulate in fruits the climacteric change alluded to above, so that large quantities can be brought uniformly to the optimum stage of ripeness at the time desired. Ammonia retards the germination of spores of decay organisms always unavoidably present to a greater or less extent on the surface of all kinds of fresh foodstuffs.

In broad retrospect, the past twenty-five years appear as an era in which scientific and practical skill has achieved remarkable results in extending the scope of storage and transport as regards the prevention of wastage. By a continuance of the same general methods-that is to say, progressive and intensive scientific analysis of the properties and behaviour of foodstuffs of all kinds and the close linking of practical application with new discovery - the next twenty-five years should see, I think, as great an advance in the quality of products as the past twenty five years has witnessed in their quantity and variety.

\title{
Special Steels
}

\author{
By Sir Robert Hadfield, Bt., F.R.s.
}

\section{INTRODUCTION}

$\mathrm{T}$ $\mathrm{HE}$ author regards it as a privilege to be invited to review in these columns the general progress of special or alloy steels during the first twenty-five years of His Majesty's reign. His pleasure in accepting this invitation is further increased by the fact that he had last year the honour of being one of the deputation from the Iron and Steel Institute to present His Majesty with the Bessemer Gold Medal, which he graciously accepted. In doing so, His Majesty was following a precedent established by Queen Victoria and continued by King Edward VII, to whom in 1906 the author himself had the honour of presenting the Medal on behalf of the Iron and Steel Institute. Thus for three generations the Royal Family has demonstrated its concern and interest for the welfare and progress of the iron and steel industry, upon which the prosperity of our country and its position in the world so largely depends.

Within the limits of space here available, it is not possible to give anything approaching a complete survey of advances in the vast field of special and alloy steels during the past quarter of a century. The story is in fact one which begins much earlier and shows during this notable period of industrial activity the vigorous expansion of the era of alloy steels, which at its commencement had become well established but was then com- paratively young. In 1929 the world's output of steel, then at its maximum production, was 120 million tons, of which no less than about 6 million tons represented alloy steels.

In reviewing progress in this period of twentyfive years it is necessary, therefore, to take account both of those newer alloy steels which it has seen initiated and also of the developments which have taken place in the use of those which had already found practical application.

The author's discovery and invention of manganese steel in 1882, as expressed by so many well-known metallurgists, marked the dawn of the age of high alloy steels. The extraordinary and valuable results then obtained led him to investigate in many other directions this hitherto practically unknown field, and later he was followed by numerous other investigators. To-day manganese steel, with modern improvements in manufacture, is used throughout the world in increasing quantities and for a greater variety of purposes than ever before. In addition, there have been developed corrosion- and heat-resisting steels, high-speed tool steels, special steels for armaments and ordnance, special structural steels, high tenacity steels, and steels with remarkable magnetic properties, whether as regards low energy losses in electrical machinery and apparatus, specially high permeability at low magnetisations, or special suitability for permanent 